\title{
Performance audiovisual digital en la Asturias del siglo XXI
}

\author{
Marcelino García Sedano \\ Universidad San Francisco de Quito
}

\section{RESUMEN}

La presencia del arte digital y en concreto de la perfomance audiovisual en Asturias, ha sido más que notoria en lo que vamos de siglo. Rastreando sus antecedentes y las características propias de esta disciplina basada en la utilización de las nuevas tecnologías, estableceremos una valoración de su alcance e importancia, no sólo a nivel local, sino también internacional.

\section{PALABRAS CLAVE:}

Live Cinema, arte y tecnología, Asturias, Lev Festival, VJing, tiempo real.

\section{ABSTRACT}

The presence of the digital art and mostly of the audiovisual perfomance in Asturias has been notorius in this Century. Seeking the antecedents and characteristics of this discipline based in the use of new technologies, we will stablish a valoration of his reach and importance not only in the local scene but in the international too.

\section{KEY WORDS:}

Live Cinema, art and technology, Asturias, Lev Festival, real time. 
1. Visualizar la música. Antecedentes del perfomance audiovisual digital

La combinación entre música e imagen ha sido una constante en la historia de las artes y ha sido explorada en su máxima profundidad a través del binomio arte y tecnología, en concreto dentro del ámbito de las nuevas tecnologías digitales, dando lugar a disciplinas específicas cuya misión principal es el desarrollo de nuevos discursos y experiencias estéticas. El siglo XXI, trae en Asturias la consolidación de la perfomance audiovisual o lo que es lo mismo, la sincronización entre música e imagen en tiempo real mediante plataformas digitales. Live Cinema, Vjing, Expanded Cinema, Directo audiovisual y demás denominaciones han sido los nombres que ha recibido este tipo de actividades artísticas ligadas a la más inmediata contemporaneidad. Para entender la importancia de estas disciplinas en la región, hay que observar el desarrollo y la presencia del arte llamado digital desde la década de los noventa y el apoyo, en gran parte institucional, que ha recibido dicha rama del arte a través de festivales, instituciones y artistas que desarrollaron y difuendieron este tipo de propuestas creativas.

Sincronizar imagen y música, visualizar la música o sonorizar la imagen, es una constante en la Historia del Arte y tiene sus origenes en las más variadas teorías, desde la física de Newton y sus 7 notas, 7 colores $^{1}$ donde estudiaba la correspondencia del espectro visible a la escala musical a los colour organs del siglo XVIII y el clavicordio ocular de Lois Bertrand Castell basado en los principios y estudios de Athanasius Kircher $^{2}$. Los espectáculos audiovisuales antiguos ligados a las artes escénicas, como la Música para los Reales Fuegos Artificiales de Haendel o el bashi japonés, el wayong javenés, los cromopianos, cromatófonos y demás artilugios como el clavilux de Thomas Wilfred, el lumígrafo de Oskar Fischinger y composiciones como Prometeo: El poema del fuego de Scriabin, destinados a explorar los límtes de la experiencia sinestésica ${ }^{3}$, fueron

1 NEWTON, Isaac, Opticks: or, a treatise of the reflexions, refractions, inflexions and colours of light, Sam Smith y Benjamin Waldorf, Londres, 1704, pág. 114.

2 En sus obras Musurgia Universalis (1650), Ars Magna sciendi sive combinatorica (1669) y Mars magna lucis et umbrae (1671), Kircher asimilaba la música a las matemáticas y por lo tanto a la explicación del mundo, cuestión que equiparaba e igualaba diversas experiencias, sobre todo la visual y la sonora.

3 La época dorada de la denominada música de colores fue el primer cuarto del siglo XX con un hecho significati- experimentos que pretendían relacionar de forma natural y lúdica, dos estímulos sensoriales tan opuestos en principio como la vista y el oido.

El cine de vanguardia y en concreto, movimientos como el Absolute Film alemán, obras de autores polacos como Stefan y Francisca Hemerson, el montaje de atracciones de Eisenstein o las primeras incursiones con computadoras a partir de los años cuarenta de Gene Youngblood, Harry Smith, los hermanos Whitney, John Mekas y otros, se puede contar también como antecedentes en la experimentación de la sincronización entre imagen y sonido de los actuales directos audiovisuales, al menos en forma y en la búsqueda de una narrativa no lineal, diferente al cine tradicional.

Los Lights Shows de los años sesenta, como antecedentes primitivos de la experiencia del directo en una ambiente underground y con una gran importancia de la música y las subculturas, sería lo más parecido a la escena de la música electrónica donde se gesta el término VJ como la figura del artista encargado de aportar visualmente a un show donde se carecía de la espectacularidad escenográfica de una banda de rock. Brotherhood of Light, The Light Sound Dimension, Joshua Light Show y Mark Boyle, son referentes de la época.

Como antecedentes verdaderamente especificos de la perfomance audiovisual en el ámbito digital, debemos tener presentes el arte generativo desarrollado a partir de los años cincuenta y sesenta a raíz del desarrollo de las computadoras y toda la teoría que rodea al fenómeno, destacando la estética generativa de Max Bense, las teorías de los sistemas del arte, del estructuralismo y las teorías cibernéticas de Norbert Wiener y Arturo Rosenblueth Stearns.

Este contexto teórico y tecnológico tan importante da lugar pronto al trabajo conjunto entre artistas y computadora, generando discursos y procesos anónimos y automatizados donde la obra resultante es el resultado de la codificación por parte del artista de unos parámetros que traducidos en logaritmos y lenguaje de programación, devienen en experiencias estéticas determinadas, imprecisas, abiertas y en definitiva en una relación estética tecnocientífica ${ }^{4}$. Max Ben-

vo, la presentación de Prometeo: el poema del fuego de Scriabin interpretada por la Russian Symphony Orchestra en el Carnegie Hall de New York en 1915 para el que usó un órgano de Rimington mejorado.

4 SERBEST, Asli y MAHALL, Mona, "Doctor illuiminatus or Ancestors of Generative Art”, en aminima22_LiveCinema, Espacio Publicaciones S.L., Barcelona, 2003, pág. 128. 
se, precursor teórico del arte electrónico, en su Estética de la Información ${ }^{5}$, conecta la informática con la semiótica del arte al establecer una estética referente a las operaciones, reglas y teoremas que aplicadas a un elemento material, producen un resultado estético. El esquema de una mediación, elemento importante y fundamental en la mayoría del arte digital viene fortalecido por el concepto griego de prographein, suma de arte y escritura y las teórias cibernéticas sobre control y sistemas que rigen a máquinas u organizaciones en imitación de los seres vivos. Esto, es la base perfecta para la colaboración estrecha, llamada por muchos coaturia, entre artista y software, creador y máquina, una constante dentro de la perfomance audiovisual, disciplina donde los conceptos como tiempo real e improvisación juegan con ese concepto de estructura abierta.

El directo audiovisual, Live Cinema o VJing es una disciplina que basa su razón de ser en la conjunción de imagen y sonido en tiempo real a través de la relación entre ser humano y tecnología, un ejemplo de la digitalización e hibridación de los medios, una disciplina única con un desarrollo histórico muy característico pero con una presencia contundente en los nuevos discursos creativos, un híbrido entre la biología y la cibernética, un sistema retroalimentado de comunicación y control ${ }^{6}$. Su característica performática, perfomance expandida según Lloyd Barret y André Brown ${ }^{7}$, le entronca directamente con otro concepto crucial en los procesos comunicativos digitales, el tiempo real. Esta característica dota a cada experiencia de Live Cinema de un valor efímero, de un énfasis en la experiencia inmediata que hace que cada una de estas experiencias concretas, sea un evento singular. Lo efímero será, una característica de la tecnologización de la cultura ${ }^{8}$ y el tiempo real según Virilio será, "la puesta en práctica de un tiempo sin relación con el tiempo histórico, es decir, un tiempo mundial ${ }^{9}$ ". Un tiempo que que

5 BENSE, Max. Estética de la Información, Comunicación, Madrid, 1972

6 BUCKSBARG, Andrew,"VJing and Live A/V Practices" en aminima22_LiveCinema, Espacio Publicaciones S.L., Barcelona, 2003 pág. 146

7 BARRETT, Lloyd y BROWN, Andrew R, "Towards a definition of the performing AudioVisualist”, en ACMA '09: Improvise: The Australasian Computer Music Conference 2009, 2-4 July 2009, Brisbane, 2009, pág. 3.

8 REASON, Mathew, Documentation, Disappearance and the Representation of Live Perfomance, Palgrave Macmillan, New York, 2006, pp. 24-25.

9 VIRILIO, Paul, El Cibermundo, la política de lo peor, Cátedra, Colección teorema, Madrid, 1999, pág. 15. en la era actual, sólo se corresponde con el de la TV y con la visualización computerizada. Dando tanta importancia a este hecho de lo efímero, el discurso queda relegado a un segundo plano en pos de la experiencia. Se vuelve a caer en el deseo histórico de la experiencia sinestésica, de la sincronización perfecta entre imagen y sonido y del discurso completo y cerrado, por lo tanto, el show audiovisual es un contrato temporal entre el perfomer y su audiencia en un contexto espacial y temporal concreto fundamentándose en las narrativas de otras disciplinas, como en un concierto musical o en una obra escénica ${ }^{10}$.

2. El caso asturiano, cultura de club, videoarte y sinestesia audiovisual. Roberto Lorenzo y Visiónica

El concepto moderno de directo audiovisual, proviene de dos ambientes específicos, el de la tecnocultura, software, hardware y su popularización y ubicuidad, sobre todo a través del ordenador portátil y el auge de la escena de club o escena de la música electrónica ${ }^{11}$. Este último aspecto, muy arraigado en Asturias desde principio de los años noventa, ve el nacimiento y el auge de la figura clave del video jockey o VJ. Artistas provenientes sobre todo de la videocreación y el diseño como Roberto Lorenzo, comienzan a animar las largas veladas de música electrónica en diversas salas de la región. El término y la figura del $\mathrm{Vj}$ ha sufrido por parte de algunos académicos el desprecio por tener su origen dentro de la escena de club con un motivo principal que no era otro que compensar la falta de escenografía inherente al show de un disc jockey $^{12}$. Basarse en esto para desprestigiar la disciplina, sería desprestigiar todo lo que conlleva desde el punto de vista cultural la escena de club

10 COOKE, Grayson.,"Liveness and the machine. Improvisation in Live Audio-Visual Perfomance" en Screen Sound n2. Australia, 2011. http://www.screensoundjournal.org/issues/n2/05.\%20SSJ\%20n2\%20Cooke.pdf, Consultado el 18 marzo de 2015.

11 SALTER, Chris, Entangled: Technology and the Transformation of Perfomance, MIT Press, Cambridge, 2010, pág 172.

12 Varios son los supuestos orígenes del término $\mathrm{Vj}$, el más ampliamente conocido es el acuñado por la cadena musical MTV haciendo referencia a la persona que seleccionaba los videos musicales y por lo tanto su orden y su relación con el resto de la programación elaborando una suerte de discurso cercano a la selección musical de un Dj. El otro el que le situa en el club neoyorquino Peppermint Lounge a finales de los años setenta. 
y la música electrónica, por lo que en la opinión de algunos autores como Ustarroz ${ }^{13}$, desde el punto de vista esencial, VJing implica sólo la sincronización entre imagen y sonido en tiempo real, algo practicado ya desde la época del cine mudo $o$ las ferias de atracciones y que se realiza desde diversas acepciones pero que en funcionamiento o esencia son lo mismo. De hecho, durante un tiempo se consideró la intención artística como atributo principal del Live cinema frente al Vjing ${ }^{14}$, incluso Brian Eno mantuvo que el Vjing era un arte de baja atención que se ubicaba entre la iluminación y el interioris$\mathrm{mo}^{15}$. Sea como sea e independientemente de su denominación, en Asturias, se comienza a ver esta disciplina en relación con la cultura de club y es en ese contexto y con esos protagonistas que se comienzan a gestar las primeras inmersiones en el contexto cultural. Desde la perspectiva histórica, Roberto Lorenzo quien había realizado la primera videoinstalación del principado en la sala Borrón en el año 1992, trasladó su concepto de imagen repetitiva, en loops y en diferentes capas a la sala La Real de Gijón en el año 1994 por primera vez ${ }^{16}$. El concepto de loop y apropiación, entronca directamente con el discurso posmoderno y tiene una relación directa con el ritmo y con el concepto de improvisación y en la construcción del significado de las obras, la narrativa, por tanto, no es tan determinante como la experiencia ${ }^{17}$. La música electrónica y su ambiente, la discoteca como lugar de exhibición, la proliferación del consumo de drogas como el extasis, son el lugar ideal de experimentación para la perfomance audiovisual. En esas primeras sesiones Rob Loren, nombre artístico de Lorenzo, utilizaba monitores de televisión convencional convenientemente apilados para acaparar una mayor superficie y a través de la tecnología U-

13 Quienes en su día defendían el término Live Cinema como algo revolucionario frente al Vjing, chocaron con autores como Ustarroz que mantenía que el lenguaje cinematográfico entendido como la gramática de las imágenes en movimiento, es único y que esta nueva modalidad, no aportaba nada al mismo más que adaptarlo a los nuevos medios, motivo no suficiente para justificar lo elevado de su discurso.

14 MAKELA, Mia, Live Cinema: language and elements, Media Lab, Helsinki University of Art and Design, Helsinki, 2006.

15 DEBACKERE, Boris \& Bretch, "El cine en la era de la creación instantánea”, en amínima22_LiveCinema, Espacio Publicaciones S.L., Barcelona, 2003 pág. 88.

16 Entrevista con Roberto Lorenzo realizada el 11 de noviembre de 2015.

17 BUCKSBARG, Andrew,"VJing and Live A/V Practices" en aminima22_LiveCinema, opus cit., pag. 146. matic y de un ordenador Amiga 2000, trasladaba su discurso visual a las salas donde se programaban esas sesiones techno. Sus primeras influencias fueron Nan June Paik, Bill Viola y la cadena MTV noche, lejos queda aun el concepto de lo digital.

El directo audiovisual se caracteriza por desarrollar esa narrativa no lineal, pero también por basarse en el concepeto de clip, de sample, de repeticón e improvisación. Estos conceptos, no sólo se relacionan con el discurso posmoderno de la cita y la apropiación ${ }^{18}$, sino también con la estructura narrativa de la música electrónica, siendo ésta el acompañamiento más común de este tipo de imágenes generadas por la figura del Vj o performer visual.

El concepto de sincronización busca la exploración de los sentidos sinestésicos y denota una extensión corporal de carácter cibernético donde el artista y la máquina, a pesar de su automatización expresa, deben sincronizarse en tiempo real de tal manera que la interfaz utilizada, computadoras y controladores midi, se convierten en prótesis sensoriales y tecnológicas, extensiones de los sentidos ${ }^{19}$. Como sea, esta intención de ajuste y esta extensión cibernética, producen un discurso abierto donde, otra vez, el azar y la coaturía entre software y hombre, derivan en un arte generativo y coprotagonizado por lo biológico y la máquina.

Bucksbarg en un artículo editado en un monográfico sobre Live Cinema en la revista a:mínima $^{20}$, revista que documentaba la relación entre arte, ciencia y tecnología editada durante un tiempo en Asturias ${ }^{21}$, diserta sobre el lenguaje específico de los directos audiovisuales pero sobre todo, sobre su percepción en el espectador. El directo audiovisual trabaja sin un sentido linguistico tradicional ya que la transmisión de sensaciones placenteras o dolorosas a través de la vista mediante códigos abstractos, en la mayoría de sus representaciones, conduce a sentimientos interiores y por lo tanto, experiencias

18 WEINRITCHER, Antonio, “Jugando en los archivos de lo real. Apropiación y remontaje en el cine de no ficción” en TORREIRO, Casimiro y CERDÁ, Josetxo editores, Documental y vanguardia, Ediciones Cátedra, Madrid, 2005. pp. 43 - 64.

19 OX, Jack y KEEFER, Cindy, On Curating Recent Digital Abstract Visual Music, http://www.centerforvisualmusic.org/Ox_Keefer_VM.htm, recuperado el 25 agosto de 2015.

20 En concreto en el número 22 publicado en el año 2003.

21 Este hecho es muy significativo ya que señala a la región como un lugar donde no sólo se acogió este tipo de disciplina, sino donde se teorizó y reflexionó, acerca de la misma. 
únicas ligadas a cada individuo ${ }^{22}$. Es pues bajo esta característica y en la más pura tradición del $\mathrm{Vj}$ vinculado con la cultura de club que Roberto Lorenzo desarrolla sus obras tempranas sincronizando imágen con los grandes nombres destacados de la música electrónica del momento y que de forma privilegiada y continua, visitan Asturias.

Sin embargo, su procedencia del mundo del arte, en concreto de la videoinstalación y su interés con la videodanza, ambos antecedentes directos del moderno directo audiovisual, le hacen pensar en la posibilidad de reunir en un evento anual esta disciplina y diferentes disertaciones sobre el encuentro entre arte y tecnología y nuevos lenguajes expresivos que no tienen porque ser siempre exclusivamente tecnológicos. Este encuentro, denominado Visiónica y con el subtítulo Arte y Cultura Avanzada y posteriormente Jornadas de Creación Audiovisual, se celebra desde el año 2004 alternando como sedes Oviedo y Gijón ${ }^{23}$. Visiónica, ha sido el primer espacio en la región donde se ha dado cabida de forma prioritaria a los directos audiovisuales, siendo esta disciplina la que define una de sus tres actividades principales junto con las conferencias y las exhibiciones.

A lo largo de sus once ediciones hasta la fecha, ha tenido como eje central diferentes temas que van desde la arquitectura avanzada, el arte sensorial, la realidad aumentada, el diseño y robótica, gastronomía y música, y entre los hechos más importantes, además de la importancia dada al Live Cinema, está haber contado con la presencia de la artista y teórica Mia Makela en la sección de conferencias en la edición de 2006 quien también ofreció un directo audiovisual bajo el seudónimo artístico Solu. Colectivos y artistas nacionales como los asturianos Normaa, FIUM, los madrileños Tektun TV, Error Visual Support, los valencianos Delacrew y los británicos Addictive TV, dentro de su importancia en la escena nacional e internacional, formaron parte de la larga lista de invitados del evento. Como algo reseñable, la hibridación con las artes escénicas y el teatro experimental de la Perfomance Lírica, Recital Trifásico y el Sueño de Martok / la Compañía LUNA en la edición de 2010.

22 Incluso en ocasiones, aunque se use foundfootage o imágenes encontradas y apropiadas de carácter figurativo, la ordenación de éstas dentro del discurso, carece de sentido narrativo tradicional.

23 El Auditorio Príncipe Felipe de Oviedo, Antiguo Instituto y Laboral centro de Arte y Creación Industrial en Gijón han sido sedes oficiales de Visiónica.
Este tipo de obras, entronca con la transdisciplinareidad o lo que Claudia Gianetti denominó el metadiseño o fusión de diversos oficios y acciones de diversos campos, danza, videocreación, música o teatro, característico de la perfomance audiovisual o videodanza en un sentido más extricto y que disuelve la inoperancia entre la imagen, el sonido, la gestualidad corporal tecnificada y expandida y el texto, añadiendo una nueva dimensión ampliada y dependiente en nuestra percepción de la tecnología ${ }^{24}$. Visiónica se ha mantenido todo este tiempo a pesar de las dificultades y es una referencia básica para entender sin duda el lugar que ocupa esta disciplina en la región asturiana.

3. Un lugar en el panorama internacional, la consolidación de la perfomance audiovisual en la región. LEV Festival y LABoral Centro de Arte y Creación Industrial

Tres años después de la primera edición de Visiónica llegará el primer LEV, siglas de Laboratorio de Electrónica Visual en 2007, año en el que nace en Gijón con la idea de posicionar a la región en el mapa de las propuestas sobre arte y tecnología, LABoral Centro de Arte y Creación Industrial.

Inaugurado el 30 de marzo de 2007, el centro aterriza en una región que según Jaime Luís Martín, no había flirteado en exceso con las nuevas tecnología, quizá como indica él mismo, por lo conservador de su mercado y el poco apoyo institucional ${ }^{25}$.

Como sea, LABoral nace para desmentir el escaso apoyo institucional y con la idea de generar debates sobre la relación arte y ciencia de importancia mundial, ya que no han sido pocas las voces, comisarios y artistas de gran relevancia internacional, que han estado presentes en talleres, debates, exposiciones y demás actividades. LABoral, dentro de lo específico de su propuesta, ha tenido más importancia en este aspecto que respuesta por parte del público de la región.

Según Rosina Gómez Baeza, su primera directora, durante muchos años, Asturias ha es-

24 GIANNETTI, Claudia, “Creación, educación y nuevas tecnologías”, en Actas Congreso La educación en Internet, http://ntic.educacion.es/w3/cinternet-educacion/actas/mesas/mesa6/mesa6i.htm recuperado el 18 junio de 2015.

25 MARTÍN, Juan Manuel, “Arte asturiano y nuevas tecnologías” en La Nueva España, 23, marzo de 2007 
tado aislada de la escena artística, aun cuando en la zona ha habido una efervescencia cultural tremenda, no se ha seguido de cerca la contemporaneidad. Ahora hay festivales importantes y comunidades artisticas de gran interés. No queremos -dice- un centro de arte contemporáneo al uso. Quisimos levantar un centro relacionado con la creación industrial para tratar los problemas que existen en torno a nuestra identidad cultural en relación con la actualidad en el ámbito artístico $^{26}$.

La idea de incorporar las nuevas tecnologías y la relación entre arte y creación industrial, pretende convertir la creatividad en este sentido en un bien cultural que impulse el conocimiento científico, algo presente desde hace tiempo en otros lugares del mundo con los que se quiere emparentar esta inciativa.

Las dos muestras con las que se inaugura este centro, Feedback y Gameworld, establecen puntos de análisis importantes sobre dos cuestiones básicas en el arte tecnológico, la primera su relación con la tradición artística y el concepto de feedback o retroalimentación presente en el arte contemporáneo y en concreto en el carácter interactivo y generativo de las nuevas tecnologías en los discursos artísticos actuales y la segunda cuestión, sobre la importancia del videojuego en el arte actual y en la experiencia tecnológica del ser humano. Este aspecto es muy importante porque el videojuego plantea el paradigma de la realidad virtual y la inmersión cibernética en la hiperrealidad con la que se interactua en tiempo real, esta característica de romper los límites espacio temporales, de la protesis cibernética y sensorial que extiende los sentidos ${ }^{27}$, guarda relación directa con la praxis del directo audiovisual en la cual, mediante la manipulación de un hardware o controlador externo, el performer modifica y crea un discurso improvisado en tiempo real.

Días antes de abrirse LABoral oficialmente y con este espíritu de internacionalidad, se celebró el primer LEV festival como uno de los encuentros entre imagen y sonido más importantes del país y con la presencia de artistas y propuestas de alta calidad internacional, una iniciativa al cargo del colectivo artístico asturiano Datatron compuesto por Nacho de la Vega y Cristina de Silva, conocidos en su faceta artística audiovisual como FIUM, que varias ediciones

26 ibidem.

27 USTARROZ, César, Teoría del Vjing. Realización y representación audiovisual a tiempo real. Apropiación de retórica y estética de las vanguardias artísticas del s. $X X$, opus cit., pag. 134. después, se ha consolidado ya como una referencia internacional perteneciendo incluso a redes tan potentes como ENCAC, European Network for Contemporary Audiovisual Creation e I.C.A.S, Internacional Cities of Advanced Sound.

La intención clara de LEV, Laboratorio de Electrónica Visual, tal y como reza su explicación en la página web de la primera edición realizada los días 23 y 24 de marzo de 2007, es llevar tanto los directos audiovisuales, como los directos musicales y el videoarte, [...] más allá de la normal concepción hedonista para convertirse, abrigados por los limites físicos de un centro de arte, en una señal inequivoca de la evolución del hombre en el arte, de la utilización de las nuevas tecnologias $[. . .]^{28}$.

Es curioso, de nuevo, la división entre lo hedonista o más vinculado a la cultura de club y lo artístico, vinculado a la industria cultural, al centro de arte. Una discusión mantenida por tiempos, algo que debido a la complejidad del entorno digital, no estoy muy de acuerdo en mantener aun. Las bases y antecedentes del directo audiovisual, antes expuestas de manera breve, son diversas, algunas con origen en la música, en el cine de variedades ${ }^{29}$, ambientes diversos, muchas veces no necesariamente considerados como de alta cultura y totalmente válidos y específicos de este tipo de manifestaciones.

El Laboratorio de Electrónica Visual, señala con su título, la analogía simbiótica entre música electrónica e imagen. Ambas disciplinas contienen en común, no sólo parecidos en su estructura básica de significado como hemos visto antes, sino que las dos necesitan una mediación tecnológica y son ejecutadas a partir de una estructura prexistente en directo, manteniendo una relación directa y cuestionable con la improvisación, lo que Ausslander denominó en inglés comprovisation (composición + improvisación) $)^{30}$. Improvisar por lo tanto, es algo complejo, ya que el tiempo real en el que la improvisación se da, se delimita en el intervalo en el que se desencadena un evento o acción y es recibido por parte del espectador, siendo este procesamiento, algo propio de la percepción sensi$\mathrm{ble}^{31}$. Autores como Grayson Cook sostienen que

\footnotetext{
28 http://www.levfestival.com/07/

29 HARK, Ina Rae (org.), Exhibition, the Film Reader, Routledge: Londres, 2002, pág. 7.

30 AUSLANDER, Philip, Liveness: Performance in a Mediatized Culture, Routledge, Londres y Nueva York, pág. 2.

31 MACKENZIE, Adrian, Transductions: Bodies and Machines at Speed, Continuum, Londres y Nueva York, , 2002, pág. 5.
} 
por todo el conocimiento previo necesario para improvisar, no hay diferencia entre componer y la improvisación ${ }^{32}$.

Estas similitudes y rasgos comunes entre imagen y música electrónica, devienen en un discurso homogéneo, un discurso que LEV pretende recoger, discutir y compartir con el público, no sólo a través de actuaciones, sino a través de conferencias, talleres, debates y todas las actividades paralelas que ha habido en diferentes ocasiones.

Desde el origen ha ocupado diversos espacios dentro de La Laboral Ciudad de la Cultura y el espacio es un concepto que define y condiciona la experiencia del directo audiovisual. El teatro sería un espacio más tradicional de observación, cercano a la experiencia del cine, los conciertos, las artes escénicas y demás. Un espacio donde la mirada está jerarquizada en oposición al escenario más caracterísitico del Directo Av de interacción más compleja que la tradicional en donde el espectador y la imagen se encuentran esporádicamente, donde la importancia reside en el lugar más que en lo proyectado ${ }^{33}$ y la imagen se come al espacio, la tecnología y la máquina deboran al hombre en una experiencia puntual, sinestésica y azarosa ${ }^{34}$. Este espacio propio, deudor de su origen en los clubs de baile y de la actitud especifica de un público permeable a una interacción triangular y compleja con el espacio, la proyección y la música es la conocida como la Nave-LABCafé, antiguamente una de las naves que acogían los talleres de la Laboral cuando era un centro educativo de formación profesional.

En relación con el funcionamiento de este tipo de espacios, continua acrecentandose el debate entre aquellas perfomances más cercanas a lo denominado Live Cinema, quizá más deudor de la gravedad y solemnidad de la sala tradicional de exhibición y la experiencia VJing, cercana al club y relacionada con los eventos de la noche. Los espacios se completan con el Jardín Botánico, la cafetería de La Laboral y diversos talleres y conferencias.

Una buena reflexión sobre el Live Cinema y una de las presencias más destacadas hasta el mo-

32 COOKE, Grayson. "Liveness and the machine. Improvisation in Live Audio-Visual Perfomance", opus cit., pag 15.

33 DEBACKERE, Boris \& Bretch, "El cine en la era de la creación instantánea” en amínima22_LiveCinema, opus cit., pag 99.

34 FRIEDBERG, Anne. Window Shopping: Cinema and the Postmodern, University of California Press, Berkeley, 1993, pag. 2. mento, fue la realizada por Peter Greenaway en el año 2009 con la presentación de The Tulse Luper Vj Perfomance. A pesar de la inclusión del término $\mathrm{Vj}$ en el título de la obra, el consagrado cineasta británico formado en las artes plásticas y siempre interesado en la confluencia entre música e imagen ${ }^{35}$, elabora para este proyecto una experiencia narrativa no tradicional a través de la combinación en directo de tres largometrajes dirigidos por él entre 2003 y 2005, una serie de television, libros y videojuegos prolongación de los mismos. Atento a la construcción de un diálogo significante con la audiencia, parte de una reestructuración digital de un trabajo audiovisual tradicional que combina y modifica considerando el trayecto en tiempo real entre el audio, la imagen y la recepción del espectador, atento por seguir el acontecimiento percibido como más inmediato e interesante por esa cercanía temporal ${ }^{36}$. Esta es la base de las transmisiones a tiempo real, desde las noticias televisadas en directo, a la asistencia a un evento perfomático audiovisual o las más tradicionales, música, danza o teatro. Greenaway parte de la sentencia de que el cine murió al convertirse en algo interactivo cuando a partir de 1983 se introduce el mando a distancia en las salas de los hogares $^{37}, \mathrm{y}$ a través de este ambicioso proyecto, lo deconstruye para mostrar en este acto, la amplitud del discurso, su apertura estructural y como no, el valor interactivo del nuevo cine.

Otro de los artistas más destacados que han pasado por Asturias, en concreto en dos ediciones del LEV es Alva Noto pseudonimo de Carsten Nicolai, artista alemán que explora la relación entre lo visual y sonoro desde la perspectiva científica, lo que acaba materializando en unos directos audiovisuales de gran calidad. El interés de su propuesta, a caballo entre la visualización minimal del sonido, un sonido estratificado en diversas y complejas capas y que contempla el error digital o glitch, recae en la investigación sobre la evolución de éste y sus posibilidades de creación y ejecución a través de las herramienta digitales. Todo esto deriva en unos espectaculares directos audiovisuales donde el concepto de sincronía, entendido como la

35 Greenaway ha trabajado con compositores como Philip Glass, Borut Krzinsnik o Michael Nyman y para este proyecto ha colaborado con Serge Dodwell.

36 BARRETT, Lloyd y BROWN, Andrew R, "Towards a definition of the performing AudioVisualist", opus cit., pág. 8.

37 WILLIS, Holly, Introduction: Exploding Ciema en New Digital Cinema. Reinventing the moving image, Wallflower paperback, Londres, 2005, pág. 1. 
tensión entre lo que se ve, se escucha y lo que hay en la mente del público ${ }^{38}$, se maneja a la perfección. Hasta tal punto, que caemos en el cuestionamiento del concepto de sinestesia que se relaciona o confunde con lo que Chion mantenía sobre la coherencia de un material audiovisual percibido como sincrónico siempre que haya un punto de sincronía entre audio e imagen cada pocos segundos. Esta ilusión de fusión de los sentidos, de percepción absoluta, es entendida por varios autores y teóricos como una experiencia sinestésica, en la que una modalidad sensorial, estimula la experiencia de otra. A pesar de que la investigación de esta posibilidad o aspecto ha sido una constante a lo largo de la historia del arte y ha sido subrayada por las posibilidades de los nuevos medios ${ }^{39}$, soy de la opinión de que a pesar de haber motivado la creación de numerosas piezas y el trabajo de muchos artistas de esta disciplina, la sinestesia es una característica que puede ser trasladado a la unión de música e imagen, pero no como su fin ultimo, sino más bien como un valor añadido y no una correspondencia natural ${ }^{40}$. Como mantiene Paul Hertz, las personas son sinestésicas, no el arte ${ }^{41}$. Dentro de esta apreciación del concepto de sincronía a colación de la obra de Alva Noto, señalar los dos potentes directos audiovisuales que ofreción en LEV, uno de ellos fue Signal realizado conjuntamente con Byetone y Bretschnei$\mathrm{der}^{42}$ en 2010 y el otro su primera propuesta en solitario en 2009.

El elenco de artistas, de renombre internacional ha sido extenso y de gran calidad. Por cuestiones de espacio no podemos sino reseñar sólo algunos y por ello quiero dar importancia al músico y artista multidisciplinar canadiense Herman Kolgen, quien presenta en el teatro Dust e Inkjet en 2011 y en 2014 Seismik. Sus trabajos audiovisuales siempre han sido de una factura exquisita y explora no sólo las relaciones

38 CHION, Michel, La audiovisión, Editorial Paidós, Barcelona, 1993, pág. 26.

39 POPPER, Frank, From technological to virtaul Art, MIT Press, cambridge, 2007, pág. 161.

40 Michael Chion refuta la idea de que haya sonidos que se correspondan de manera natural con una imagen, ya que es una convención del autor utilizar en sus manifestaciones un sonido o imagen concreta. CHION, Michel, La audiovisión, Editorial Paidós, Barcelona, 1993 pág. 13.

41 HERTZ, Paul, "Synesthetic Art - An Imaginary Number?" en Leonardo Vol 32, no 5, MIT Press, San Francisco, 1999, pág. 400.

42 Los tres son productores musicales fundadores de la plataforma Raster Norton, un referente musical que hace especial hincapié en las posibilidades sonoras y sobre todo en su representación visual. complejas de la tecnología con el entorno inmediato, sino los límites de las posibilidades representativas y tecnológicas. Dust, representa a través de partículas similares al polvo lo que Panayotis Kokoras denominó morphopiesis o el hecho de que los objetos sonoros son animados o puestos en movimiento en el espacio musical al ser transformados. Esta teoría se aplica a objetos sonoros, pero alude también a objetos visuales que pueden tener una trayectoria o ejecución coordinada en conjunto con los anteriores, buscando coherencia estética y afecto. Segón Kokoras, este funcionamiento libera al productor audiovisual y le permite construir y deconstruir su discurso con total libertad ${ }^{43}$. Un término complejo que nació de la música pero que sin lugar a dudas pone en relevancia la importancia y conveniencia de teorizar desde esta perspectiva.

Inject, obra premiada en la edición de 2010 de Ars Electrónica, facilita la visualización de las transformaciones neurosensoriales del cuerpo humano al ser sumergido en un líquido. Ciencia y arte se dan la mano, lo biológico y lo digital se abrazan en un binomio de factura exquisita y forma de perfomance audiovisual.

De igual carácter, Seismik construye su perfomance a través del monitoreo de las señales tectónicas y de fricción de las capas terrestres. La transformación de estas señales en otras visuales y sonoras, entronca directamente con el concepto del arte generativo en el que la mediación de una computadora y un software, transforma una señal en otra, dependiendo de la máquina y de la voluntad parcial del artista a partes iguales y entendida siempre desde el punto de vista de lo aleatorio. Derrida reflexionó sobre esto cuando definió que en el entorno digital, improvisar permite la unión del evento y de la máquina, siendo el evento lo afectivo y la máquina lo aestético, una definición perfecta del arte generativo, de la fusión de lo inintencional y de lo orgánico y la importancia de la mediación en el arte digital ${ }^{44}$.

Esta mediación ha sido popularizada, y por ende la disciplina, por el desarrollo de los ordenadores portátiles, su ubicuidad y sobre todo, el desarrollo de software específico para la perfomance visual, o programas de edición de imagen en directo. Dentro de esta dinámica, LEV festival organizó un

43 KOKORAS, Panayiotis A., "Morphopoiesis: A general procedure for structuring form" en Electronic Musicological Review, Volume IX, Brasil, octubre 2005. file://D|/REM/_REM/REMv9-1/kokoras.html, recuperado el 21 de febrero de 2015.

44 DERRIDA, Jacques, Without Alibi (ed and trans Kamuf, P), Stanford University Press, California, 2002, pág. 72. 
taller sobre Resolume, programa específico de edición en 2009 y presentó varios controladores MIDI, contemplando también la importancia de las herramientas dentro de este panorama específico. La escena define un perfil concreto de artista perfomático audiovisual como una mezcla entre un hacker y un activista que merodea casi siempre en la frontera de la autoproducción de las herramientas y la autogestión de sus discursos dando una impresión underground muy acentuada ${ }^{45}$.

En cuanto a la presencia asturiana de artistas audiovisuales, destacar las intervenciones de Normaa en varias ediciones, del colectivo Th3hold y Cristina Busto, que con su presencia en el festival demuestra el apoyo y la difusión de la escena local.

Atención aparte merece la experimentación con la danza y los nuevos medios que ha mantenido una presencia activa en el festival y la escena artística regional en los últimos años. Los nuevos medios disuelven la fisicidad de las diferentes disciplinas y favorecen la interactividad, expanden el cuerpo, parte importante en las artes escénicas y lo tecnifican, desarrollando discursos acerca de cómo afectan estas tecnologías a nuestra existencia, sus consecuencias fisiológicas y psicológicas y la relación entre audiencia y performer ${ }^{46}$.

Como antecedente importante, en el año 1999, el ex Fura dels Baus y pionero en la utilización de la tecnología en la perfomance Marceli Antúnez, presentó en Oviedo su obra Afasia dentro del marco del Festival Diáspora. Afasia fue una perfomance mecatrónica en la que a través de un exoesqueleto el autor enviaba órdenes a una computadora que modificaba unas imágenes proyectadas, unos robots y la música en una interpretación libre de la Odisea de Homero ${ }^{47}$.

Diversas ediciones de LEV presentaron diferentes espectáculos que unían teatro, danza y nuevas tecnologías. Desde KINDERTOTENLIEDER una obra que juega con la interpretación de la fantasía o la realidad interpretada por Gisèle Vienne, Dennis Cooper \& KTL (Stephan 0’Malley \& Meter Rehberg), pasando por Electric Girl de Apostalia Papadamaki y Quasi Stellar o la unión entre sonido, imagen y cuerpo de A.lter $S$-essio de Fabrice Planquette y las coreógrafas

45 BARRETT, Lloyd and BROWN, Andrew R, "Towards a definition of the performing AudioVisualist", opus cit., pág. 11.

46 DIXON, Steve, Digital perfomance. A history of New Media in Theather, Dance, Perfomance Art and Installation, The MIT Press, Cambridge, 2007, pág. 5.

47 Información de la página web del artista el día 21 de noviembre de 2015 http://marceliantunez.com/work/afasia/ japonesas Yoko Higashino y Yum y Zoetrope de Rui Horta y Micro Audio.

Mención destacada la obra Trinity presentada en 2014 en el teatro Jovellanos de Gijón, una obra de danza interactiva audiovisual creda por el creador Oscar Sol a.k.a Electronic Performers y la coreógrafa austriaca Iris Heitzinger junto a Ramón Prada, compositor asturiano de la música. El nombre viene de la estructura trinitaria compuesta por el movimiento de la danza, el sonido y los visuales que explora de manera experimental la percepción del espacio en una interacción constante entre los tres elementos.

\section{A modo de conclusión}

Han sido muchas las obras, artistas y actividades que han pasado por LEV a lo largo de todas las ediciones hasta el momento y no se han podido nombrar por cuestiones de espacio. Lo que sí es incuestionable es la gran importancia que tiene este festival a nivel internacional y junto a Visiónica y la consolidada y pionera escena electrónica asturiana más o menos experimental, podemos afirmar que Asturias, ha sido y es un referente en el arte y su confluencia con la tecnología y la ciencia. El impulso institucional de grandes centros como LABoral ha sido vital, pero la existencia de una escena muy interesada en los nuevos discursos, tanto desde la perspectiva del creador, de los gestores culturales, promotores y público, sobre todo en lo referente a la perfomance audiovisual, ha sido determinante. Basta revisar las programaciones de otros centros y festivales foráneos para darse cuenta de que los principales artistas, tecnologías y académicos han estado visibles en la región al mismo tiempo que en otros lugares del panorama internacional. El desarrollo de la disciplina performática audiovisual, ha sido contemporáneo al de otros lugares del mundo y ha seguido los mismos procesos, las mismas fases y ha tenido las mismas consecuencias con un gran impacto en la región, sobre todo, volviendo a insistir, en un público entusiamado, sensibilizado y habituado a muestras y discursos de gran calidad. Asturias es un espacio de exhibición y reflexión para los nuevos discursos artísticos y toda una referencia al respecto. Que ciudades como Gijón aparezcan en redes como ENCAC o ICAS, no hacen más que reforzar los lazos con el panorama audiovisual digital internacional y consolidar a la región como un semillero cultural importante, un espacio a tener en cuenta, una parte viva de la historia. 
